\title{
biomolecules
}

ISSN 2218-273X

www.mdpi.com/journal/biomolecules/

Article

\section{Redox-Regulated Pathway of Tyrosine Phosphorylation Underlies NF- $\kappa$ B Induction by an Atypical Pathway Independent of the 26S Proteasome}

\section{Sarah Cullen ${ }^{1}$, Subramaniam Ponnappan ${ }^{2}$ and Usha Ponnappan 1,2,*}

1 Department of Microbiology and Immunology, University of Arkansas for Medical Sciences, Little Rock, AR 72205, USA; E-Mail: cullensarahjane@gmail.com

2 Department of Geriatrics, University of Arkansas for Medical Sciences, Little Rock, AR 72205, USA; E-Mail: SPonnappan@uams.edu

* Author to whom correspondence should be addressed; E-Mail: UPonnappan@uams.edu; Tel.: +1-501-296-1252; Fax: +1-502-686-5359.

Academic Editor: Jürg Bähler

Received: 4 September 2014 / Accepted: 28 January 2015 / Published: 9 February 2015

\begin{abstract}
Alternative redox stimuli such as pervanadate or hypoxia/reoxygenation, induce transcription factor NF- $\mathrm{B}$ by phospho-tyrosine-dependent and proteasome-independent mechanisms. While considerable attention has been paid to the absence of proteasomal regulation of tyrosine phosphorylated $\mathrm{I} \kappa \mathrm{B} \alpha$, there is a paucity of information regarding proteasomal regulation of signaling events distinct from tyrosine phosphorylation of I $\mathrm{B} \alpha$. To delineate roles for the ubiquitin-proteasome pathway in the phospho-tyrosine dependent mechanism of NF- $\kappa \mathrm{B}$ induction, we employed the proteasome inhibitor, Aclacinomycin, and the phosphotyrosine phosphatase inhibitor, pervanadate (PV). Results from these studies demonstrate that phospho-IкB $\alpha(\mathrm{Tyr}-42)$ is not subject to proteasomal degradation in a murine stromal epithelial cell line, confirming results previously reported. Correspondingly, proteasome inhibition had no discernable effect on the key signaling intermediaries, Src and ERK1/2, involved in the phospho-tyrosine mechanisms regulating PV-mediated activation of NF- $\kappa \mathrm{B}$. Consistent with previous reports, a significant redox imbalance leading to the activation of tyrosine kinases, as occurs with pervanadate, is required for the induction of NF- $\mathrm{KB}$. Strikingly, our studies demonstrate that proteasome inhibition can potentiate oxidative stress associated with PV-stimulation without impacting kinase activation, however, other cellular implications for this increase in intracellular oxidation remain to be fully delineated.
\end{abstract}




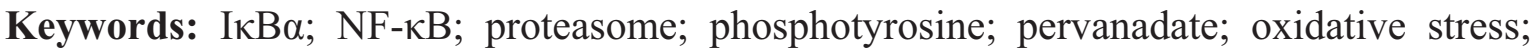
hypoxia/reoxygenation

\section{Introduction}

The nuclear factor- $\mathrm{kB}(\mathrm{NF}-\mathrm{\kappa B})$ family of transcription factors is comprised of evolutionarily conserved and structurally-related interacting proteins that bind to DNA. NF- $\kappa B$ plays a crucial role in the transcriptional regulation of genes involved in controlling cell proliferation, differentiation, apoptosis, inflammation, and stress responses, in addition to other biological processes. Consistent with its role in regulating the immune response, abnormal NF- $\kappa \mathrm{B}$ regulation has been linked to cancer, aging, inflammatory and autoimmune diseases, septic shock, viral infections, and improper immune development. Several activating mechanisms for NF- $\mathrm{B}$ have been described, each of which is inducible in a cell and stimuli-specific manner.

Activation of NF- $\kappa \mathrm{B}$ by proinflammatory cytokines belonging to the tumor necrosis factor (TNF) and interleukin (IL)-families is termed the canonical pathway, whereas activation of a specific Ser/Thr-specific IкB kinase (IKK) signalosome complex, active in B-cells, is a second and alternative pathway. The third group of mechanisms, collectively termed "atypical pathways", comprises chemical and physiological stress factors [1], as well as oxidative [2], genotoxic [3], and organelle stress [4]. Despite the diversity amongst these signaling pathways, there are considerable similarities in terms of the underlying mechanisms associated with NF- $\mathrm{B}$ induction. For example, phosphorylation-dependent inactivation of $I \kappa B$ proteins, such as $I \kappa B \alpha$ or $p 100$, dominates as the prevailing mechanism for the vast majority of these NF- $\kappa B$ signaling pathways [5]. Such a phosphorylation pathway has been extensively characterized for I $\mathrm{B} \alpha$ and entails phosphorylation on Ser-32 and Ser-36 by the IKK complex, followed by subsequent ubiquitination and degradation via the $26 \mathrm{~S}$ proteasome pathway. The less-characterized, atypical pathway of NF- $\kappa B$ induction involves tyrosine phosphorylation of $\mathrm{I} \kappa \mathrm{B} \alpha$. In contrast to serine phosphorylation of I $\mathrm{I} B \alpha$, tyrosine phosphorylation of I $\kappa \mathrm{B} \alpha$ at Tyr-42 generally does not invoke its ubiqutin-mediated degradation by the proteasome [6,7]. Instead, NF- $\kappa \mathrm{B}$ activation by tyrosine phosphorylation of I $\kappa \mathrm{B} \alpha$ relies on a poorly defined mechanism whereby phospho-I $\mathrm{B} \alpha$ dissociates from $\mathrm{NF}-\kappa \mathrm{B}[8]$.

Our fundamental understanding of the interplay between tyrosine phosphorylation and NF- $\kappa \mathrm{B}$ activation is principally derived from studies employing pervanadate, a phosphotyrosine phosphatase inhibitor. Pervanadate (PV) irreversibly inhibits tyrosine phosphatases while also inducing cellular oxidation, presumably due to phospho-tyrosine dependent activation of the cellular NADPH oxidases $[9,10]$. The pro-oxidant effects of PV are likely to have a stimulatory effect on protein tyrosine kinases (PTKs) because redox-sensitive mechanisms regulate the activation of cellular PTKs [11]. Hence, based on the cellular effects of PV, the plausible mechanisms by which PV activates NF- $\kappa B$ are two-fold: inhibition of protein tyrosine phosphatases and activation of protein tyrosine kinases. In support of this concept, an elegant study by Fan et al. demonstrated that c-Src-dependent tyrosine phosphorylation of I $\mathrm{B} \alpha$ and subsequent activation of NF- $\mathrm{KB}$ is contingent on intracellular $\mathrm{H}_{2} \mathrm{O}_{2}$ [12]. As added proof that hyperoxic conditions underlie the phospho-tyrosine-dependent mechanism of NF- $\kappa \mathrm{B}$ induction, 
PV-induced NF- $\kappa B$ signaling mechanisms closely mimic those observed during hypoxia/reoxygenation, ischemia/reperfusion, and stimulation with growth factors [6,7,13-17]. Despite advances in our understanding of the interplay between redox mechanisms and phospho-tyrosine-dependent activation of NF- $\kappa B$, the physiological significance of this redox-sensitive mechanism of NF- $\kappa B$ induction remains largely ill-defined.

Recent studies regarding "bortezomib resistance" have highlighted the biological significance of mechanisms of NF- $\kappa \mathrm{B}$ induction, which are resistant to proteasome inhibition [18,19]. Hence, the in vivo relevance of the phospho-tyrosine-dependent mechanism of NF- $\kappa$ B induction may ultimately be defined due to its distinction as a proteasome-independent mechanism of NF- $\mathrm{BB}$ activation. Based on this prevision, we sought to investigate how proteasome inhibition affects facets of phospho-tyrosine-dependent NF- $\mathrm{B}$ signaling, both related and unrelated to tyrosine phosphorylation of I $\mathrm{B} \alpha$.

While considerable attention has been paid to the absence of proteasomal regulation of tyrosine phosphorylated $\mathrm{I} \kappa \mathrm{B} \alpha$, there is a paucity of information regarding proteasomal regulation of signaling events distinct from tyrosine phosphorylation of $\mathrm{I} \kappa \mathrm{B} \alpha$. Further, this includes an incomplete understanding of the role for ubiquitin-like modifiers, such as NEDD8 and SUMO, in the signaling events of the atypical NF- $\mathrm{B}$ pathway. To delineate unexplored roles for the ubiquitin-proteasome pathway in the phospho-tyrosine dependent mechanism of NF- $\mathrm{BB}$ induction, we employed the proteasome inhibitor, Aclacinomycin, and the phosphotyrosine phosphatase inhibitor, pervanadate. Results from these studies demonstrate that phospho-IкB $\alpha$ (Tyr-42) is not subject to proteasomal degradation in a murine stromal epithelial cell line, confirming results previously reported in HeLa and Jurkat cell lines [7,12]. Correspondingly, proteasome inhibition had no discernable effect on the key signaling intermediaries - Src and ERK1/2 - involved in the phospho-tyrosine mechanisms regulating PV-mediated activation of $\mathrm{NF}-\kappa \mathrm{B}$. Consistent with previous reports, a significant redox imbalance leading to the activation of tyrosine kinases, as occurs with Pervanadate, is required for the induction of NF- $\kappa \mathrm{B}$ in this cell type. Strikingly, our studies demonstrate that proteasome inhibition can potentiate oxidative stress associated with PV-stimulation; however, the cellular implications for this increase in intracellular oxidation remain to be delineated. In particular, this study highlights a regulatory mechanism underlying the inhibition of tyrosine phosphatases, a concomitant activation of tyrosine kinases accompanying cellular oxidation, and a significant role for proteasome inhibition in the potentiation of these responses.

\section{Results}

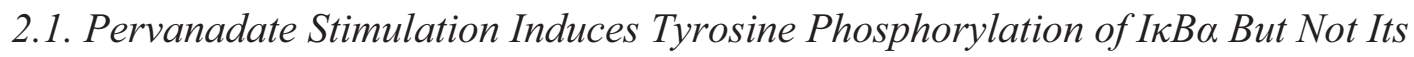
Proteolytic Degradation

$\mathrm{TNF} \alpha$-mediated activation of NF- $\mathrm{BB}$ induction has been demonstrated to invoke serine phosphorylation of the inhibitory $\mathrm{I} \kappa \mathrm{B}$ proteins followed by ubiquitination and degradation via the $26 \mathrm{~S}$ proteasome pathway [5]. In contrast, NF- $\kappa \mathrm{B}$ activation by pervanadate involves tyrosine phosphorylation of I $\mathrm{B} \alpha$ and is not contigent upon proteasomal degradation of $\mathrm{I} \kappa \mathrm{B} \alpha[6,7]$. To test whether PV-mediated activation of $\mathrm{NF}-\kappa \mathrm{B}$ occurs by a proteasomal-independent mechanism in a murine stromal cell line, we subjected ILU-18 cells to short-term activation with TNF $\alpha$ or PV and then tested cytosolic lysates by immunoblotting with an antibody recognizing $\mathrm{I} \kappa \mathrm{B} \alpha$. While $\mathrm{I} \kappa \mathrm{B} \alpha$ is no longer detected in response to TNF $\alpha$ treatment, 
I $\kappa \mathrm{B} \alpha$ remains in the cytosol following short-term PV treatment, indicating absence of I $\mathrm{B} \alpha$ degradation in PV-induced NF-kB (Figure 1A).

A

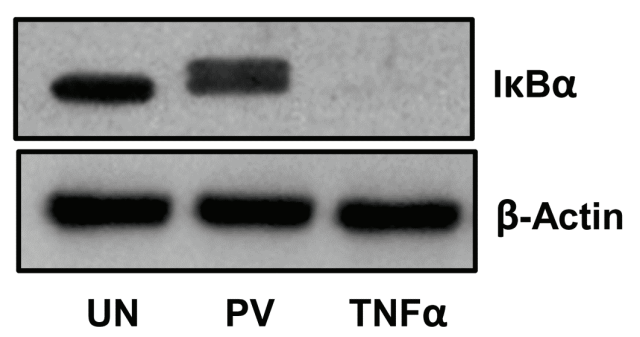

B

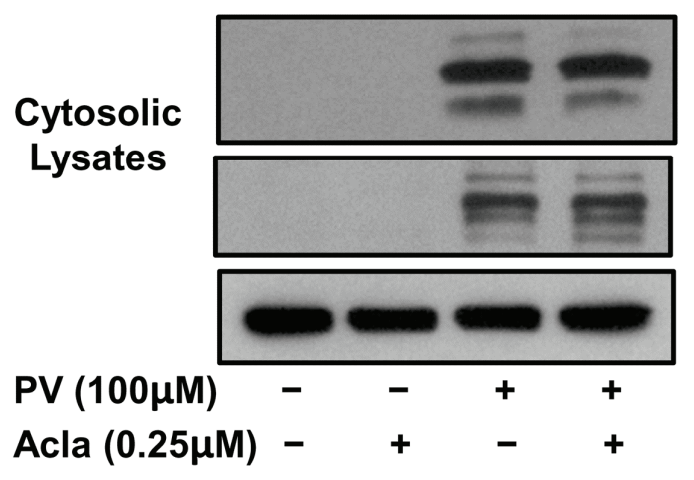

Phospho-IKB $\alpha$

(Tyr-305)

Phospho-IKB $\alpha$

(Tyr-42)

$\beta$-Actin

Figure 1. Pervanadate (PV) stimulation induces tyrosine phosphorylation of I $\kappa \mathrm{B} \alpha$ but not its proteolytic degradation. (A) ILU-18 cells were either left untreated or treated with Pervanadate $(100 \mu \mathrm{M})$ or TNF- $\alpha(20 \mathrm{ng} / \mathrm{mL})$ for $20 \mathrm{~min}$. At the end of treatment, cytosolic lysates were obtained and $30 \mu \mathrm{g}$ protein from each lysate was resolved by sodium dodecyl sulfate polyacrylamide gel electrophoresis (SDS-PAGE). Resolved proteins were detected by Western blotting using antibody to nuclear factor of kappa light polypeptide gene enhancer in B-cells inhibitor, alpha $(\mathrm{I} \kappa \mathrm{B} \alpha)$ and enhanced chemiluminescence (ECL). The blot was stripped and re-probed with antibody to $\beta$-actin to ensure equal protein loading. (B) ILU-18 cells were treated with PV $(100 \mu \mathrm{M})$ for $20 \mathrm{~min}$, with or without prior treatment with Aclacinomycin [Acla] $(0.25 \mu \mathrm{M})$ for $2 \mathrm{~h}$. At the end of incubation, cells were washed and cytosolic lysates prepared. As controls, cell lysates were made from ILU-18 cells either left untreated or treated for 140 min with $0.25 \mu \mathrm{M}$ Aclacinomycin alone. Lysates, equalized for $30 \mu \mathrm{g}$ protein, were resolved using SDS-PAGE, followed by Western blotting using a phospho-specific antibody recognizing IкB $\alpha$ (Tyr-42) or (Tyr-305). After stripping, the blot was re-probed with antibody to $\beta$-actin to demonstrate equal protein loading.

To elucidate whether PV-mediated NF- $\mathrm{BB}$ activation occurs by a mechanism involving tyrosine phosphorylation, we next assessed if both in the absence and presence of proteasome inhibitor (Aclacinomycin), I $\mathrm{K} \mathrm{B} \alpha$ undergoes tyrosine phosphorylation [20]. By employing immunoblotting with an antibody recognizing phospho-IкB $\alpha$ (Tyr42 or Tyr305), we now demonstrate that PV induces tyrosine phosphorylation of I $\mathrm{BB} \alpha$ at Tyr-42 and Tyr305, both in the absence and presence of proteasome inhibitor (Figure 1B). Overall, these results demonstrate that in response to PV stimulation, tyrosine phosphorylation of I $\mathrm{B} \alpha$ occurs, independently of proteasome catalytic function. 
2.2. Pretreatment with Inhibitors of Src and MEK but not p38, PI3K, JNK and IKK Complex Interfere with PV-Induced NF- $\kappa B$ Activity

Pervanadate mediates both the coordinated inhibition of cellular tyrosine phosphatases as well as the activation of cellular tyrosine kinases. Kinase families, which are prone to activation by PV, include the Src and Syk family of tyrosine kinases and the family of serine/threonine specific kinases, MAPK [12,15,21,22]. To delineate if these kinases are involved in NF- $\kappa$ B-dependent transcription induced by $\mathrm{PV}$, we employed a luciferase reporter assay, which had previously been shown to be dependent on PV-mediated NF- $\kappa$ B activity. Pretreatment with Piceatannol, the resveratrol metabolite and tyrosine kinase inhibitor, resulted in a significant reduction in PV-induced NF- $\mathrm{BB}$-dependent luciferase activity, thus indicating an important role for the Src/Syk family of tyrosine kinases in PV-mediated, NF- $\kappa B$-dependent luciferase expression (Figure $2 \mathrm{~A}$ ). Furthermore, the mitogen-activated protein kinase kinase (MEK) inhibitor, PD98059, substantially interfered with PV-mediated NF-kB activity, indicating that MEK also contributes to pervanadate-mediated NF- $\kappa B$ activation (Figure $2 \mathrm{~A}$ ).

To elucidate which family of tyrosine kinases is principally involved in PV-dependent NF- $\kappa \mathrm{B}$ activation, we subjected ILU-18 cells to short-term activation with pervanadate (20 min) and then examined Syk and phospho-Syk by immunoblotting with antibodies recognizing Syk \& tyrosine-phosphorylated Syk. Though Syk was detected, tyrosine phosphorylation of Syk was not observed following PV treatment in ILU-18 cells (Figure 2B). In contrast, we confirmed that c-Src is indeed phosphorylated following PV stimulation in this cell line by employing an antibody to phospho-Src (Figure 3). Given the PV-mediated phosphorylation of c-Src, we sought to determine if Src kinase was necessary in PV-dependent NF- $\kappa \mathrm{B}$ activity. Employing a selective inhibitor of Src, we pretreated cells with Src Kinase Inhibitor I, before subjecting them to PV-stimulation. As depicted in Figure $2 \mathrm{C}$, pretreatment with Src Kinase Inhibitor I significantly inhibited PV-induced NF- $\kappa B$ activity, thus demonstrating the involvement of Src kinase in PV-induced activation of NF- $\mathrm{BB}$. Since c-Src kinase has been implicated in the tyrosine phosphorylation of $\mathrm{I} \kappa \mathrm{B} \alpha$, we evaluated if in the ILU-18 cell line, Src kinase plays a role in the tyrosine phosphorylation of $\mathrm{I} \kappa \mathrm{B} \alpha$ at tyrosine 42. Pretreatment with Src Kinase Inhibitor I abrogated PV-dependent, tyrosine phosphorylation of $\mathrm{I} \kappa \mathrm{B} \alpha$ (Tyr-42), as determined by immunoblotting with an antibody recognizing phospho-I $\mathrm{KB} \alpha$ (Tyr-42) (Figure 2D). Taken together, these results demonstrate that

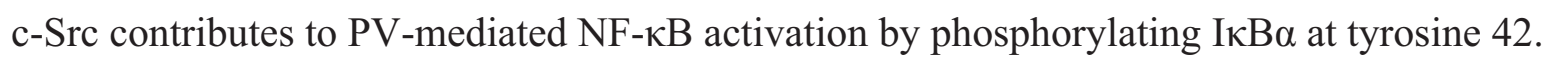

As JNK, p38, and PI3K subfamilies have been connected with stress conditions conducive for inactivation of tyrosine phosphatases [23], we next tested their involvement in PV-mediated NF- $\mathrm{BB}$ signaling by employing inhibitors to the kinase activity of each of these pathways (Figure 2E). Unlike MEK and the Src family kinases, the involvement of JNK, p38, and PI3K activity was found not to be critical in pervanadate-mediated NF- $\mathrm{KB}$ activation. As IKK complex activation following activation of PKD has been demonstrated to be necessary in $\mathrm{H}_{2} \mathrm{O}_{2}$-induced NF- $\mathrm{KB}$ responses in epithelial cells [24], we next tested the role of IKK in PV-induced NF- $\mathrm{BB}$ activity. Employing a cell permeable IKK Nemo-binding peptide (IKK-NBD) as an inhibitor of IKK complex formation, we demonstrate that pretreatment with IKK-NBD did not inhibit pervanadate-mediated luciferase expression, indicating that luciferase expression is independent of the IKK complex. TNF $\alpha$ induced IL-6 expression was, however, dependent on IKK (Figure 2F). Thus, pretreatment with Src and MEK inhibitors, but not JNK, p38, PI3K, and IKK 
complex inhibitors, modulated pervanadate-induced luciferase expression, providing evidence that Src and MEK kinases are key signaling intermediaries in PV-mediated NF-kB induction.

A

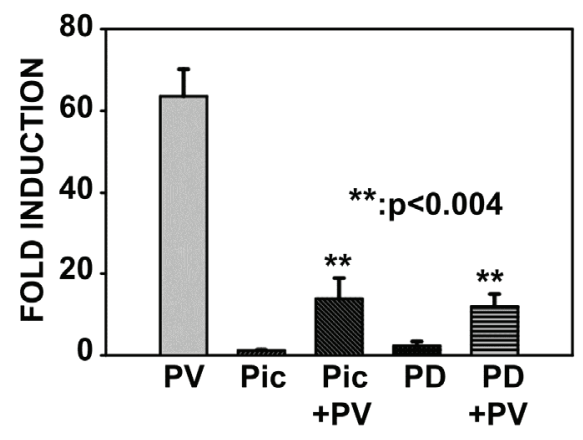

B

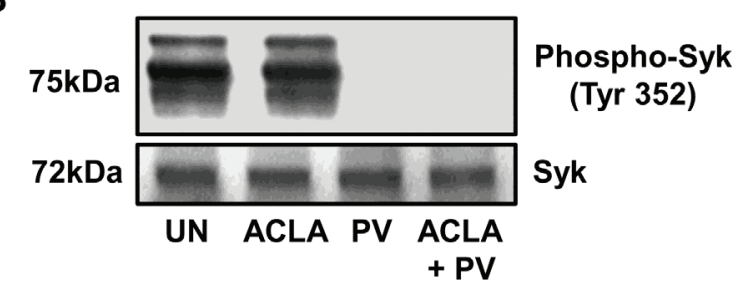

C

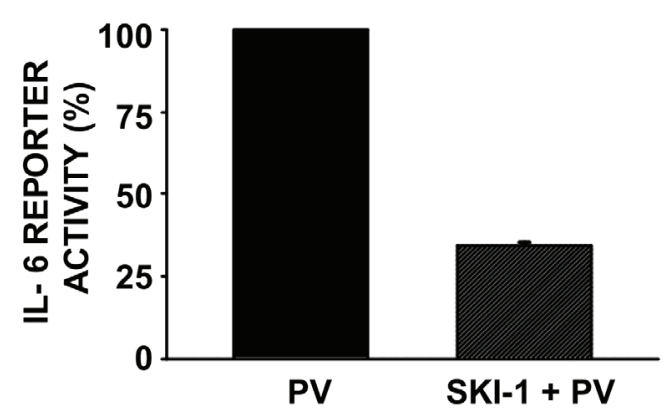

$\mathbf{F}$
D
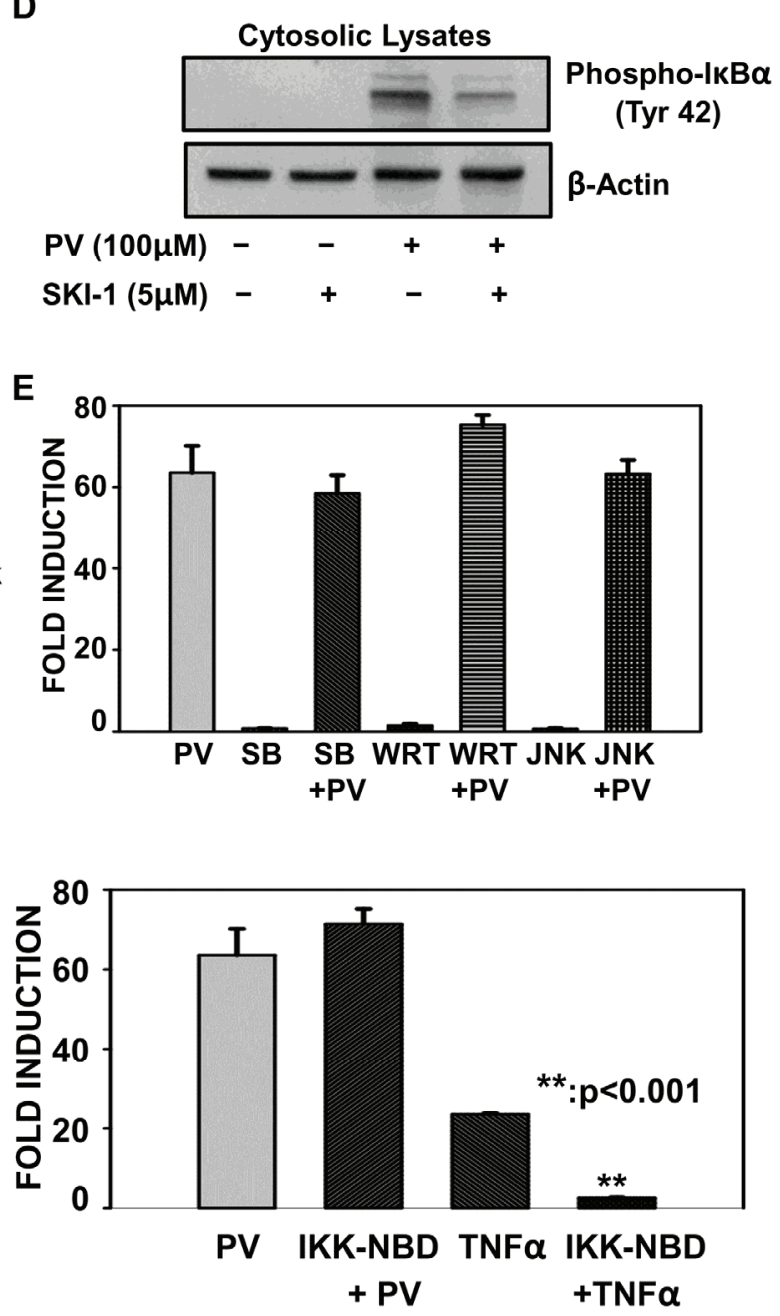

Figure 2. Pretreatment with inhibitors of Src and mitogen-activated protein kinase kinase (MEK) but not p38, PI3K, c-Jun N-terminal kinase (JNK) and IkappaB kinase (IKK) complex interfere with PV-induced NF- $\kappa$ B activity. (A) ILU-18 cells were pretreated with $75 \mu \mathrm{M}$ Piceatannol (Pic.) for $45 \mathrm{~min}$ or $20 \mu \mathrm{M}$ PD98059 (PD.) for $30 \mathrm{~min}$ followed by activation with $100 \mu \mathrm{M}$ pervanadate for $18 \mathrm{~h}$. Cells treated with $100 \mu \mathrm{M}$ pervanadate, $75 \mu \mathrm{M}$ Piceatannol, or $20 \mu \mathrm{M}$ PD98059 for $18 \mathrm{~h}$, served as controls. At the end of $18 \mathrm{~h}$, lysates were obtained and luciferase activity was determined employing the Promega luciferase assay kit. Fold induction represents a ratio of luciferase activity obtained in treatment-induced to that of untreated cells. Data represents mean \pm standard error obtained from four independent experiments, following normalization. ** Denotes significant difference at $p<0.004$, between treatment groups. (B) ILU-18 cells were treated with PV $(100 \mu \mathrm{M})$ for $20 \mathrm{~min}$, with or without prior treatment with Aclacinomycin $(0.25 \mu \mathrm{M})$ for $2 \mathrm{~h}$. At the end of incubation, cells were washed and cytosolic lysates prepared. As controls, cell lysates were made from ILU-18 cells left untreated or treated $140 \mathrm{~min}$ with $0.25 \mu \mathrm{M}$ Aclacinomycin alone. Lysates, equalized for $30 \mu \mathrm{g}$ protein, were resolved using SDS-PAGE, followed by Western blotting using antibodies for phospho-Syk (Tyr-352) and, as a control, Syk. (C) ILU-18 cells were treated with $100 \mu \mathrm{M}$ 
pervanadate for $18 \mathrm{~h}$, with or without pretreatment for $6 \mathrm{~h}$ with $2 \mu \mathrm{M}$ Src Kinase Inhibitor I (SKI-1). As controls, cells were either left untreated or subjected to treatment with $2 \mu \mathrm{M}$ Src Kinase Inhibitor I for $24 \mathrm{~h}$ [25]. As described in (A), a luciferase assay was performed. Normalized data are presented as \% activity with fold induction values from PV-treated cells set at $100 \%$. Data represents mean \pm S.E. from duplicates derived from two independent experiments. (D) ILU-18 cells were treated with $100 \mu \mathrm{M}$ pervanadate for $20 \mathrm{~min}$, with or without pretreatment for $4 \mathrm{~h}$ with $5 \mu \mathrm{M}$ Src Kinase Inhibitor I (SKI-1). At the end of incubation, cells were washed and cytosolic lysates prepared. As controls, cell lysates were made from ILU-18 cells left untreated or treated 260 min with $5 \mu \mathrm{M}$ Src Kinase Inhibitor I alone. Lysates, equalized for $30 \mu \mathrm{g}$ protein, were resolved using SDS-PAGE, followed by Western blotting using a phospho-specific antibody recognizing I $\mathrm{I} \mathrm{B} \alpha(\mathrm{Tyr}-42)$. The blot was stripped and re-probed with antibody to $\beta$-actin to ensure equal protein loading. (E) ILU-18 cells were treated with $100 \mu \mathrm{M}$ pervanadate, 100nM SB23580 (SB.-p38 Kinase inhibitor), $10 \mu \mathrm{M}$ Wortmannin (WRT-PI3K inhibitor), or $40 \mathrm{nM}$ JNK Inhibitor for $18 \mathrm{~h}$. ILU-18 cells were also pretreated for $1 \mathrm{~h}$ with $40 \mathrm{nM} \mathrm{JNK}$ Inhibitor or for $30 \mathrm{~min}$ with either $100 \mathrm{nM}$ SB23580 or $10 \mu \mathrm{M}$ Wortmannin followed by activation with $100 \mu \mathrm{M}$ pervanadate for $18 \mathrm{~h}$. Fold induction was determined as in (A). Data represents mean \pm S.E. from four independent experiments. (F) ILU-18 cells were either pretreated with $10 \mu \mathrm{M}$ IKK-NBD for $1 \mathrm{~h}$ or left untreated. After $1 \mathrm{~h}$, cells were either treated with $100 \mu \mathrm{M}$ PV or $20 \mathrm{ng} / \mathrm{mL} \mathrm{TNF} \alpha$ for $18 \mathrm{~h}$, yielding the following treatments: Untreated, PV, IKK-NBD+PV, TNF $\alpha$, IKK-NBD+TNF $\alpha$. Fold induction was determined as in (A). Data represents mean \pm S.E. from duplicates derived from two independent experiments. ${ }^{* *}$ Denotes significant difference at $p<0.001$, between treatment groups.

\subsection{Proteasome Inhibition Does Not Alter PV-Mediated Activation of Src or MEK Kinases}

As PV represents a proteasome-independent mechanism of NF- $\mathrm{BB}$ induction, we assessed the effect of proteasome inhibition on the signaling pathways identified in PV-induced NF- $\kappa$ B activity, e.g., Src and MEK kinases. To determine the effect of proteasome inhibition on the activation of the Src and ERK 1/2 kinases, we subjected ILU-18 cells to short-term activation with PV, both in the absence or presence of proteasome inhibitor, and then tested cytosolic lysates by immunoblotting with antibodies recognizing phosphorylated c-Src and ERK 1/2. As depicted in Figure 3, both in the absence or presence of proteasome inhibitor, pervanadate induced the phosphorylation of c-Src and ERK 1/2. Thus, loss in proteasomal catalytic activity does not interfere with the phospho-tyrosine dependent mechanisms that regulate $\mathrm{PV}$-mediated induction of $\mathrm{NF}-\kappa \mathrm{B}$.

\subsection{PV-Mediated Activation of NF- $\kappa B$ Involves Oxidative Stress}

While the precise mechanisms responsible for PV-mediated induction of NF- $\mathrm{BB}$ remain to be fully explored, it is known that the redox imbalance accompanying pervanadate stimulation plays a significant role in both tyrosine phosphorylation of I $\kappa \mathrm{B} \alpha$ and $\mathrm{NF}-\kappa \mathrm{B}$ transcriptional activity [12]. To assess if PV acts as a potent pro-oxidant in ILU-18 cells, we measured the generation of reactive oxygen species (ROS) by employing the oxidant-sensing fluorescent probe, $\mathrm{H}_{2}$ DCF-DA. Compared to the induction of 
ROS by the exogenous addition of $\mathrm{H}_{2} \mathrm{O}_{2}$, PV treatment was more potent at inducing intracellular DCF fluorescence (Figure 4A). Thus, exposure to PV induces ROS generation, as primarily reported in Jurkat and Ramos cells [26].

To ascertain the functional significance of redox imbalance, we determined if cellular tyrosine phosphorylation induced by PV was dependent upon intracellular oxidation. By measuring oxidative stress with the $\mathrm{H}_{2}$ DCF-DA probe, we determined that pretreatment of ILU-18 cells with the antioxidant, $\mathrm{N}$-acetylcysteine (NAC), significantly impaired the pro-oxidant effects of PV [25]. Based on this observation, we pretreated ILU-18 cells with NAC to boost nonenzymatic detoxification of reactive electrophiles and free radicals and then measured PV-dependent phospho-tyrosine accumulation by immunoblotting with an anti-phosphotyrosine antibody. As depicted in Figure 4B, pretreatment with NAC inhibited the induction of cellular tyrosine phosphorylation by PV. Additionally, NAC pretreatment blocked the tyrosine phosphorylation of I $\mathrm{B} \alpha$ (Tyr-42) accompanying PV-stimulation (Figure 4C). Taken together, these results demonstrate that the generation of ROS and subsequent intracellular oxidation by PV plays a prominent role in tyrosine phosphorylation of cellular proteins, including $\mathrm{I} \kappa \mathrm{B} \alpha$.

To further support the contention that NF- $\kappa \mathrm{B}$ activation by PV occurs as a result of oxidative stress, we evaluated the effect of NAC pretreatment on PV-mediated NF- $\kappa \mathrm{B}$ activity. As expected, the ROS scavenging effects of NAC offset Pervanadate-mediated oxidative stress, resulting in levels of luciferase activity on a par with background levels (Figure 4D). This reversal by NAC demonstrates that Pervanadate is inducing luciferase expression by the generation of ROS.

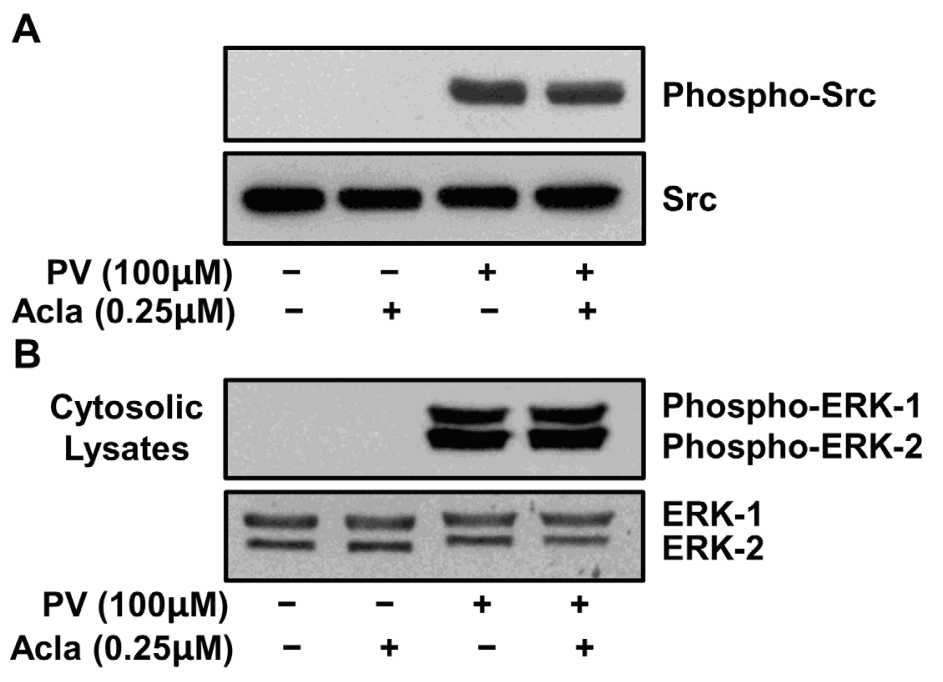

Figure 3. Proteasome inhibition does not impact PV-mediated activation of Src or MEK kinases. ILU-18 cells were treated with PV $(100 \mu \mathrm{M})$ for $20 \mathrm{~min}$, with or without prior treatment with Aclacinomycin $(0.25 \mu \mathrm{M})$ for $2 \mathrm{~h}$. At the end of incubation, cells were washed and cytosolic lysates prepared. As controls, cell lysates were made from ILU-18 cells left untreated or treated with $0.25 \mu \mathrm{M}$ Aclacinomycin alone for $140 \mathrm{~min}$. Lysates, equalized for $30 \mu \mathrm{g}$ protein, were resolved using SDS-PAGE, followed by Western blotting using antibodies to phospho-Src (Tyr-416) and Src (A); or antibodies to phospho-p44/p42 ERK1/2 (Thr-202/Tyr-204) and ERK1/2 (B). 
A

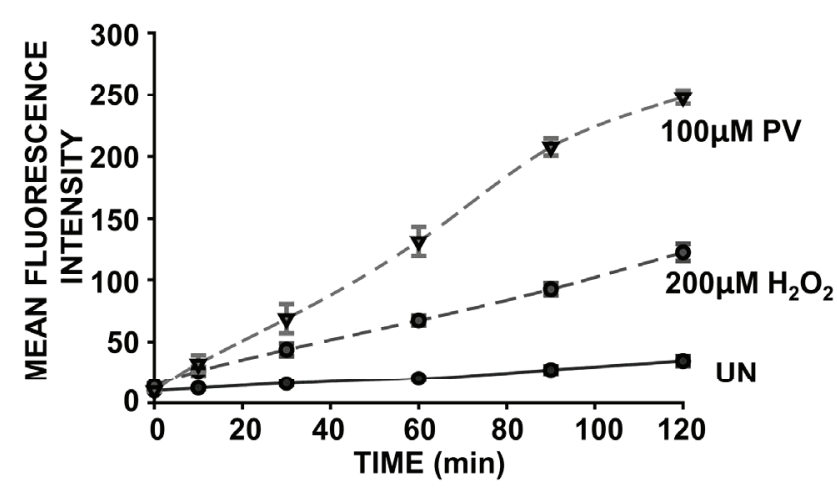

B

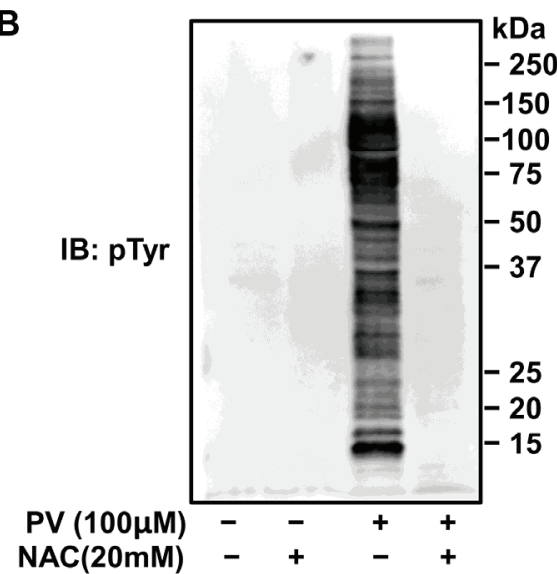

C

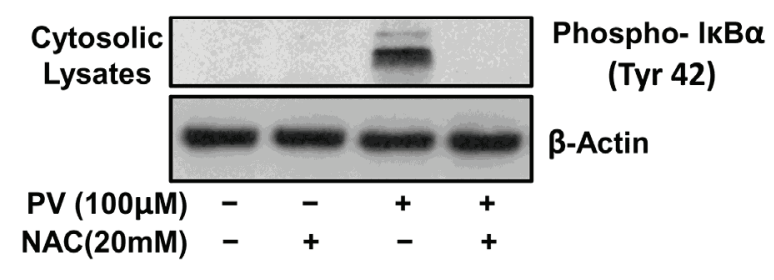

D

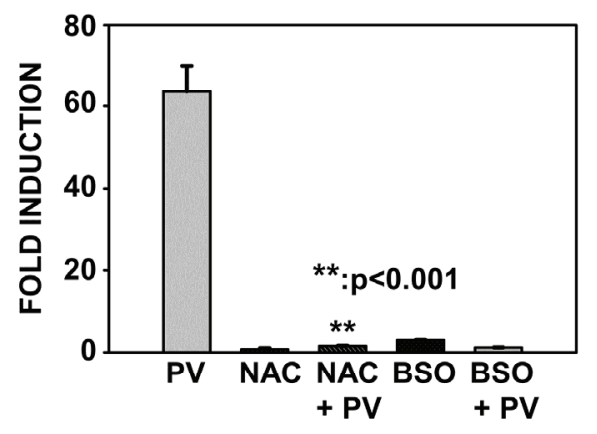

Figure 4. PV-mediated activation of NF- $\kappa B$ involves oxidative stress. (A) ILU-18 cells were washed and briefly incubated in 1X Hank's Balanced Salt Solution (HBSS), prior to incubation with $10 \mu \mathrm{M} \mathrm{H} \mathrm{H}_{2}$ DCF-DA for $30 \mathrm{~min}$ at $37{ }^{\circ} \mathrm{C}$ in the dark. At the end of the incubation, cells were washed and resuspended in 1X HBSS. Intracellular reactive oxygen species (ROS) generation was detected following addition of PV $(100 \mu \mathrm{M})$ or $\mathrm{H}_{2} \mathrm{O}_{2}$ $(200 \mu \mathrm{M})$, as described in the methods section. (B) ILU-18 cells were either untreated or treated with NAC (20 mM) for $2 \mathrm{~h}$. After media replacement, cells were selectively treated with PV $(100 \mu \mathrm{M})$ for $20 \mathrm{~min}$. At the end of incubation, cells were washed and cytosolic lysates prepared. As controls, cell lysates were made from ILU-18 cells left untreated or treated with $20 \mathrm{mM}$ NAC alone for $140 \mathrm{~min}$. Lysates, equalized for $30 \mu \mathrm{g}$ protein, were resolved using SDS-PAGE, followed by Western blotting using an antibody specific to Phospho-Tyrosine residues. Molecular weights derived from standards are indicated in $\mathrm{kDa}$. (C) Cytosolic lysates (30 $\mu \mathrm{g})$, obtained as in (B), were resolved using SDS-PAGE, followed by Western blotting using a phospho-specific antibody recognizing $\mathrm{I} \kappa \mathrm{B} \alpha$ (Tyr-42). After stripping, the blot was re-probed with antibody to $\beta$-actin to demonstrate equal protein loading. (D) ILU-18 cells were either untreated or treated with NAC $(20 \mathrm{mM})$ for $2 \mathrm{~h}$. After media replacement, cells were selectively treated with PV $(100 \mu \mathrm{M})$ for $18 \mathrm{~h}$. Additionally, ILU-18 cells were treated with $100 \mu \mathrm{M} \mathrm{H}_{2} \mathrm{O}_{2}$ for $18 \mathrm{~h}$ or subjected to treatment with $200 \mu \mathrm{M}$ BSO for $24 \mathrm{~h}$. Lysates obtained were evaluated for luciferase acitivity, as described previously. Data obtained from at least four independent experiments are presented; values represent data means \pm standard error. ** Denotes significant difference at $p<0.001$, between treatment groups. 
Having established that Pervanadate induces NF- $\kappa \mathrm{B}$ activation by oxidative stress, we next tested whether perturbations in the redox balance were sufficient to induce NF- $\kappa$ B activity. For this, NF$\kappa \mathrm{B}$-dependent luciferase expression was analyzed using Buthionine-sulfoximine (BSO) treatment. BSO mediates its pro-oxidant effects by inhibiting the enzyme responsible for synthesis of the primary intracellular thiol and ROS scavenger, glutathione (GSH). BSO treatment of ILU-18 cells for $24 \mathrm{~h}$ resulted in only a two-fold induction of luciferase activity (Figure 4D). These BSO results would likely have been higher if $\mathrm{BSO}$ was co-administered with a pro-oxidant, thereby more potently disrupting the

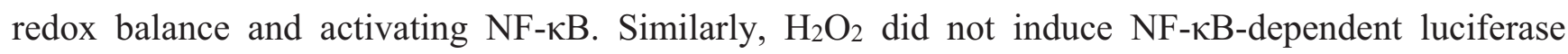
activity (Figure 4D). This finding is consistent with our observations that in ILU-18 cells, $\mathrm{H}_{2} \mathrm{O}_{2}$ was neither a potent pro-oxidant (Figure 4A) nor an effective inducer of cellular tyrosine phosphorylation [25]. Collectively, these results indicate that a significant redox imbalance leading to the activation of tyrosine kinases, as occurs with Pervanadate, is required for the induction of NF- $\kappa \mathrm{B}$ in this cell type.

\subsection{Proteasome Inhibition Potentiates Oxidative Stress Associated with PV-Stimulation}

While proteasome inhibition has no effect on the phospho-tyrosine dependent mechanisms that regulate PV-mediated induction of NF- $\kappa$ B (Figure 3), it remains unclear how proteasome inhibition impacts the intracellular redox balance, which is also critically necessary for PV-mediated induction of NF- $\kappa$ B. By measuring generation of ROS with the $\mathrm{H}_{2}$ DCF-DA probe, we observed that pretreatment with proteasome inhibitors potentiated oxidative stress generated by pervanadate stimulation (Figure 5A). ILU18 cells treated with proteasome inhibitor alone induced intracellular oxidation near background levels, thereby affirming that proteasome inhibition does not independently induce oxidative stress (Figure 5A). Despite the amplification in intracellular ROS generation, pretreatment with proteasome inhibitor did not intensify cellular tyrosine phosphorylation accompanying PV treatment (Figure 5B). Additionally, pretreatment with proteasome inhibitor did not interfere with redox-dependent tyrosine phosphorylation induced by PV (Figure 5B). Thus, while loss in proteasomal catalytic activity enhances PV-mediated oxidative stress, this effect appears to have no discernable impact on redox-dependent tyrosine phosphorylation by PV.

For an assessment of the long-term implications of proteasome inhibition on PV-induced ROS generation, we measured intracellular glutathione (GSH) following $18 \mathrm{~h}$ of PV stimulation. As GSH participates in the enzymatic conversion of $\mathrm{H}_{2} \mathrm{O}_{2}$ to $\mathrm{H}_{2} \mathrm{O}$, depletion of this antioxidant is indicative of oxidative stress within the cell. Both in the absence and presence of proteasome inhibitor, GSH levels declined significantly after $18 \mathrm{~h}$ exposure to PV. Yet, despite pretreatment with proteasome inhibitor, PV-associated loss in functional GSH was nearly equivalent; in other words, proteasomal inhibition did not result in an elevation in GSH depletion (Figure 5C). In agreement with ROS data, treatment with proteasome inhibitor alone had no effect on GSH levels (Figure 5C), indicating that loss in proteasomal catalytic activity alone is not sufficient to induce intracellular oxidation in ILU-18 cells. Overall, these results show for the first time that proteasome inhibition can potentiate oxidative stress associated with PV-stimulation; however, the cellular source and implications for this increase in intracellular oxidation have to yet to be determined. 

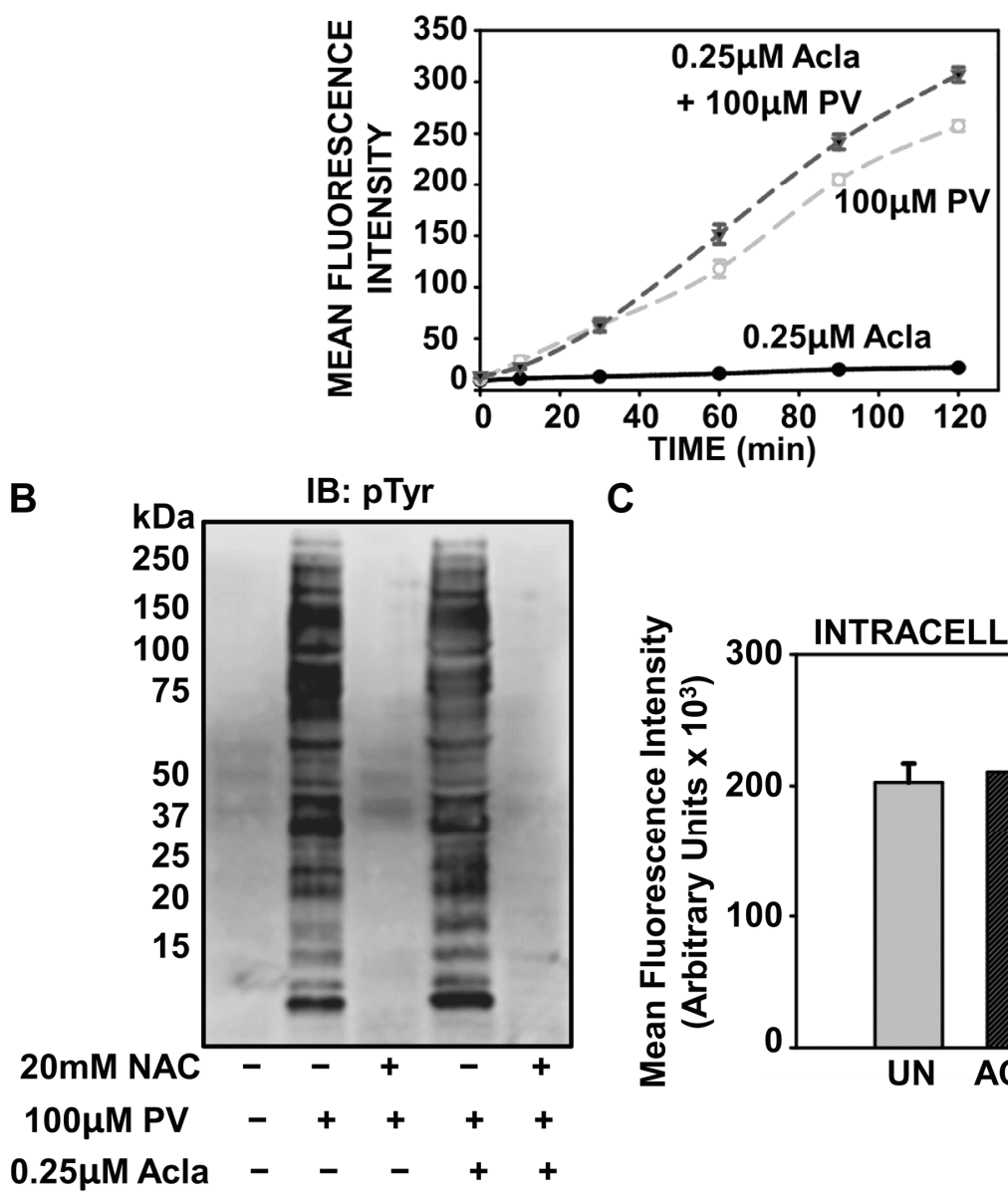

C

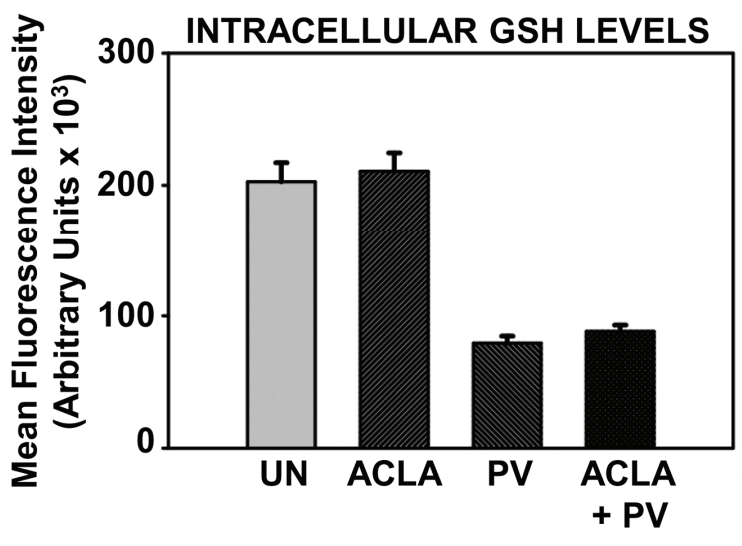

Figure 5. Proteasome inhibition potentiates oxidative stress associated with PV-stimulation. (A) ILU-18 cells were either left untreated or treated with $0.25 \mu \mathrm{M}$ Acla for $2 \mathrm{~h}$. Following treatment with proteasome inhibitor, cells were washed and briefly incubated in 1X HBSS, prior to incubation with $10 \mu \mathrm{M} \mathrm{H} \mathrm{H}_{2} \mathrm{DCF}-\mathrm{DA}$ for $30 \mathrm{~min}$ at $37{ }^{\circ} \mathrm{C}$ in the dark. At the end of the incubation, cells were washed and resuspended in $1 \mathrm{X}$ HBSS. Intracellular oxidation was detected following addition of PV $(100 \mu \mathrm{M})$, as described in the methods section. (B) ILU-18 cells were either left untreated or pretreated with $0.25 \mu \mathrm{M}$ Acla for $2 \mathrm{~h}$, in the presence or absence of $20 \mathrm{mM}$ NAC. Media was then replaced and cells were selectively treated with PV $(100 \mu \mathrm{M})$ for $20 \mathrm{~min}$. At the end of incubation, cells were washed and cytosolic lysates prepared. Lysates, equalized for $30 \mu \mathrm{g}$ protein, were resolved using SDS-PAGE, followed by Western blotting using an antibody specific to Phospho-Tyrosine residues. Molecular weights derived from standards are indicated in $\mathrm{kDa}$. (C) ILU-18 cells were treated with $100 \mu \mathrm{M}$ pervanadate for $18 \mathrm{~h}$, with or without pretreatment for $2 \mathrm{~h}$ with $0.25 \mu \mathrm{M}$ Aclacinomycin. As controls, cells were either left untreated or subjected to treatment with $0.25 \mu \mathrm{M}$ Aclacinomycin for $20 \mathrm{~h}$. At the end of treatment, cells were lysed; $2 \mu \mathrm{L}$ of MCB and GST were added to each sample and incubated at $37{ }^{\circ} \mathrm{C}$ for $15 \mathrm{~min}$. Fluorescence was measured at an excitation wavelength of $340 \mathrm{~nm}$ and emission wavelength of $465 \mathrm{~nm}$. Data obtained from duplicates of at least two independent experiments are presented; values represent mean fluorescence intensity $(\mathrm{MFI}) \pm$ standard error. 


\section{Discussion}

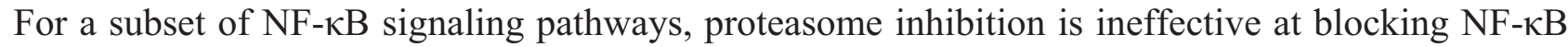
induction because these pathways rely on proteasome-independent mechanisms for releasing NF- $\mathrm{B}$ from its inhibitor $\mathrm{I} \kappa \mathrm{B} \alpha$. For instance, the atypical pathway of NF- $\kappa \mathrm{B}$ induction entails upstream signaling mechanisms, which culminate in tyrosine phosphorylation of $\mathrm{I} \kappa \mathrm{B} \alpha$ and subsequent dissociation from $\mathrm{NF}-\kappa \mathrm{B}$ without the involvement of the proteasome. Considerable attention has been paid to the absence of proteasome-mediated degradation of $\mathrm{I} \kappa \mathrm{B} \alpha$ within this subset of NF- $\kappa \mathrm{B}$ signaling pathways; however, the effect of proteasome inhibition on additional upstream signaling events in these pathways remains unexplored. For this reason, we delineated the effect of proteasome inhibition on facets of phospho-tyrosine-dependent NF- $\mathrm{BB}$ induction, both related and unrelated to tyrosine phosphorylation of I $\mathrm{I} B \alpha$.

We demonstrate in a murine bone marrow-derived stromal cell line that, upon short-term activation with PV, cytosolic I $\kappa \mathrm{B} \alpha$ undergoes tyrosine phosphorylation but not proteasome-mediated degradation - in keeping with data reported from previous studies employing HeLa and Jurkat cell lines $[7,12]$. Additionally, as in HeLa and Jurkat cell lines, phosphorylation of $\mathrm{I} \kappa \mathrm{B} \alpha$ at Tyr-42 is regulated by the tyrosine kinase, c-Src. Based on immunoblotting, we demonstrate that c-Src assumes its active form, regardless of proteasome inhibition. Since these results analyzed Src kinase activation following short-term exposure to PV, we cannot exclude the possibility that after prolonged exposure to PV, a discrepancy in Src kinase activity may ensue from the combined treatment of proteasome inhibitor and $\mathrm{PV}$, as compared to PV treatment alone. This stems from studies describing the active form of Src as a preferential target for degradation by the proteasome [27,28]. The intriguing possibility that proteasome down-regulates PV-dependent Src activity introduces the idea of the proteasome as a key negative regulator of signaling associated with the atypical NF- $\kappa \mathrm{B}$ pathway. At the present time, there is no evidence in the literature, which either supports or refutes this hypothesis. However, stabilization of Src by the chaperone, Hsp 90, has recently been shown to be an essential mechanism in the Src-regulated phosphorylation of $\mathrm{I} \kappa \mathrm{B} \alpha^{\mathrm{Y} 42}$ accompanying PV stimulation [29]. This emphasizes that mechanisms associated with the regulation of Src have a profound impact on PV-mediated induction of NF- $\kappa \mathrm{B}$. Accordingly, Src represents a "lynch pin" in the induction of NF-kB by PV, and as such, constitutes a prime target for negative regulators of the atypical NF- $\kappa B$ pathway.

Whereas c-Src kinase phosphorylates I $\mathrm{KB} \alpha$ at Tyr-42 [12], the tyrosine kinase, c-Abl, has been implicated in the phosphorylation of $\mathrm{I} \kappa \mathrm{B} \alpha$ at Tyr-305 [30]. The precise role of phospho-I $\mathrm{B} \alpha(\mathrm{Tyr}-305)$ in the atypical NF- $\mathrm{KB}$ signaling pathway remains elusive because the stimuli generally associated with atypical NF- $\kappa$ B responses have yet to be vetted as inducers of phospho-I $\mathrm{B} \alpha(\mathrm{Tyr}-305)$. Thus far, overexpression of either a constitutively-active c-Abl protein or Hepatitis $\mathrm{C}$ virus nonstructural protein $5 \mathrm{~A}$ (NS5A) has been conclusively shown to induce the tyrosine phosphorylation of IкB $\alpha$ at Tyr-305 [30,31]. Due to discrepancies in the findings between these studies, tyrosine phosphorylation of $\mathrm{I} \kappa \mathrm{B} \alpha^{\mathrm{Y} 305}$ appears to modulate both its stability as well as its ability to simultaneously undergo tyrosine phosphorylation at Tyr-42, in a stimulus-dependent manner. To our knowledge, PV has not been characterized as an inducer of phospho-IкB $\alpha(\mathrm{Tyr}-305)$ but as we demonstrate here, PV can indeed induce tyrosine phosphorylation of $\mathrm{I} \kappa \mathrm{B} \alpha$ at both Tyr-42 and Tyr-305 residues. Without rigorous, biochemical experimentation, we are unable to definitively elucidate whether PV induces pools of 
I $\mathrm{B} \alpha$ which are uniquely phosphorylated at each tyrosine residue (Tyr-42 or Tyr-305), dually modified at each tyrosine residue (Tyr-42 and Tyr-305), or a combination of both. Given that Tyr-42/-305 phospho-I $\mathrm{B} \alpha$ has been demonstrated to undergo calpain-mediated degradation in NS5A overexpressing cells, it is noteworthy that PV-induced phospho-IкB $\alpha$ does not undergo any degradation in ILU-18 cells. Further, pretreatment with the calpain inhibitor, E64D, prior to PV-treatment did not interfere with NF- $\kappa \mathrm{B}$ activity [25]. Nevertheless, our demonstration that PV is capable of inducing tyrosine phosphorylation of $\mathrm{I} \kappa \mathrm{B} \alpha$ at both tyrosine residues provides the assurance that PV can be used to evaluate the crosstalk not only between these two tyrosine phosphorylation sites but also the potential crosstalk between tyrosine phosphorylation and sumoylation.

Strikingly, modification of I $\mathrm{B} \alpha$ by either tyrosine phosphorylation or sumoylation confers similar outcomes in terms of the stability. Since I $\kappa \mathrm{B} \alpha$ undergoes modification by SUMO-1 at the same lysine residue targeted for ubiquitination (K21), sumoylated $\mathrm{I} \kappa \mathrm{B} \alpha$ is resistant to ubiquitin-mediated degradation by the proteasome [32]. Accordingly, modification of I $\mathrm{B} \alpha$ by SUMO-1 has emerged as the prototypical example of the stabilizing effect of sumoylation. Similarly, tyrosine phosphorylation has been found to protect $\mathrm{I} \kappa \mathrm{B} \alpha$ from the cytokine-induced serine phosphorylation which precedes ubiquitin-mediated degradation by the proteasome [33]. Despite the overlap in function between these two modifications, the possibility that I $\mathrm{B} \alpha$ is dually modified by SUMO-1 and tyrosine phosphorylation remains unexplored.

Finally, the objective of this study was to understand the effect of proteasome inhibition on facets of phospho-tyrosine-dependent NF- $\mathrm{kB}$ signaling, both related and unrelated to tyrosine phosphorylation of I $\kappa \mathrm{B} \alpha$. While proteasome inhibition had no discernable effect on the early signaling events accompanying PV-mediated NF- $\kappa \mathrm{B}$ induction, proteasome inhibition did potentiate oxidative stress associated with $\mathrm{PV}$-stimulation. The cellular implications for this increase in intracellular oxidation are uncertain in this cell type, however, there is mounting evidence that proteasome inhibition, in combination with oxidative stress, has appreciable effects on cellular viability, clearance of oxidatively damaged proteins, detoxification capacity of antioxidant enzymes, and inflammation in other cell types [34-37]. In neuronal cells, both acute and chronic inhibition of proteasome activity alters mitochondria homeostasis, resulting in overproduction of reactive oxygen species (ROS) by dysfunctional mitochondria [37,38]. Contrary to these reports, in our system, proteasome inhibition alone did not induce an increase in ROS. Instead, proteasome inhibition had an additive effect on cellular oxidation induced by PV. We investigated the possibility that the combination of proteasome inhibition and oxidative stress unduly stressed detoxification capacity of GSH but despite pretreatment with proteasome inhibitor, PV-associated loss in functional GSH was nearly equivalent. However, a potential effect of proteasome inhibition on additional antioxidants, such as catalase and superoxide dismutase remains to be tested. In fact, this possibility is supported by a recent study delineating the effect of pretreatment with proteasome inhibitor on liver ischemia/reperfusion (I/R). In this study, Alexandrova et al. demonstrated that compared to I/R alone, the combination of proteasome inhibition and I/R disproportionately stressed the activities of the antioxidant enzymes, catalase and superoxide dismutase [39].

In summary, the results presented here reiterate that early signaling events associated with atypical pathway of NF- $\kappa \mathrm{B}$ induction are proteasome-independent. While mechanisms and biological significance of $\mathrm{I} \kappa \mathrm{B} \alpha$ tyrosine-phosphorylation in protein stability remain unclear, these studies highlight the potential for an intriguing interplay between redox regulation, tyrosine phosphorylation, and the atypical mechanism of NF-kB induction. 


\section{Experimental Section}

\subsection{Antibodies \& Reagents}

Phospho-Tyrosine, phospho-p38 MAPK (Thr-180/Tyr-182), phospho-p44/p42 MAPK (Thr-202/Tyr-204), Src, and phospho-Src (Tyr-416) antibodies were obtained from Cell Signaling Technology (Danvers, MA, USA). Antibodies for phospho-specific I $\mathrm{IB} \alpha$ (Tyr-42) and (Tyr-305) were purchased from ECM Biosciences (Versailles, KY, USA). All other antibodies were from Santa Cruz Biotechnology (Santa Cruz, CA, USA). Anti-IgG coupled to horseradish peroxidase and enhanced Chemiluminescence (ECL) reagents were from ThermoScientific (Rockford, IL, USA). All fine chemicals, unless otherwise mentioned, were obtained from Sigma Chemical Company (St. Louis, MO, USA). Electrophoresis supplies and Molecular weight standards were from BioRad (Hercules, CA, USA). Aclacinomycin, Lactacystin, SB23580, Wortmannin, and JNK Inhibitor II, and PD98059 were from EMD Millipore (Bilerica, MA, USA). Murine TNF $\alpha$ was purchased from R\&D Systems (Minneapolis, MN, USA). 2,7-dichlorodihydrofluorescein diacetate $\left(\mathrm{H}_{2} \mathrm{DCF}-\mathrm{DA}\right)$ was purchased from Life Technologies (Grand Island, NY, USA). Piceatannol was obtained from Enzo life sciences (Farmingdale, NY, USA).

\subsection{Cell Culture}

ILU-18 cells were maintained in RPMI supplemented with $2 \mathrm{mM}$ glutamine, 100 units $/ \mathrm{mL}$ penicillin, $100 \mu \mathrm{g} / \mathrm{mL}$ streptomycin, and $10 \%$ fetal bovine serum. This cell line was stably transfected with a murine IL-6 minigene designated ILU, containing the entire IL-6 promoter and first intron, including the 3'UTR. Derived from the bone marrow stromal cell line, ${ }^{+/}$LDA.11, ILU-18 cells were kindly provided by Dr. Charles O'Brien (UAMS, Little Rock, AR, USA).

\subsection{Preparation of Cytosolic and Nuclear Extracts and Western Blotting}

Cells were washed twice in cold phosphate-buffered saline, resuspended in cytosolic extraction buffer containing $10 \mathrm{mM}$ Hepes, pH 7.8, $10 \mathrm{mM} \mathrm{KCl,} 2 \mathrm{mM} \mathrm{MgCl}$, $0.1 \mathrm{mM}$ EDTA, $1 \mathrm{mM}$ DTT, and protease inhibitor cocktail, and incubated on ice for $20 \mathrm{~min}$. Nonidet P-40 was added to the cells to obtain a final concentration of $0.5 \%$, followed by mixing and centrifugation at $12,000 \times g$ for 5 min at $4{ }^{\circ} \mathrm{C}$. Supernatants, which corresponded to cytosolic extracts, were collected. Nuclear extracts were prepared by resuspending the pellet in nuclear extraction buffer containing $50 \mathrm{mM}$ Hepes, $\mathrm{pH} 7.8,50 \mathrm{mM} \mathrm{KCl}, 300 \mathrm{mM} \mathrm{NaCl}$, $0.1 \mathrm{mM}$ EDTA, $1 \mathrm{mM}$ DTT, 10\% glycerol, and protease inhibitor cocktail. Proteins were extracted by vortexing for $60 \mathrm{~min}$ at $4{ }^{\circ} \mathrm{C}$ and clarified by centrifugation at $14,000 \times g$ for $10 \mathrm{~min}$. Supernatants which represented both cytosolic and nuclear extracts were collected and analyzed for protein content by Bio-Rad protein assay. Cell lysates equalized for protein were resolved by SDS-PAGE, transferred to nitrocellulose, immuno-blotted with specific antibodies, and detected using anti-IgG coupled to horseradish peroxidase (HRP) followed by ECL. 


\subsection{Measurement of Intracellular Oxidation Using $\mathrm{H}_{2} \mathrm{DCF}-\mathrm{DA}$}

ILU-18 cells $\left(1 \times 10^{6} / \mathrm{mL}\right)$ were washed with $1 \mathrm{X}$ Hank's Balanced Salt Solution (HBSS) before resuspending the cells in $1 \mathrm{~mL} \mathrm{HBSS}$ and equilibrating at $37^{\circ} \mathrm{C}$ for $15 \mathrm{~min}$. At the end of equilibration, cells were treated with $10 \mu \mathrm{M} \mathrm{H} \mathrm{H}_{2} \mathrm{DCF}-\mathrm{DA}$ and incubated further for $30 \mathrm{~min}$ at $37{ }^{\circ} \mathrm{C}$ in the dark. After washing the cells with $1 \mathrm{X}$ HBSS, cells were resuspended in $1 \mathrm{~mL}$ of $1 \mathrm{X}$ HBSS. ROS generation was monitored following addition of PV $(100 \mu \mathrm{M})$ or $\mathrm{H}_{2} \mathrm{O}_{2}(200 \mu \mathrm{M})$ and detected using a LS-50 spectrofluorometer (Perkin Elmer Corporation, Norwalk, CT, USA) at excitation wavelength of $480 \mathrm{~nm}$ and emission wavelength of $525 \mathrm{~nm}$.

\subsection{Measurement of Intracellular GSH}

Intracellular GSH levels were assayed as described previously [40]. Briefly, $100 \mu \mathrm{L}$ of ice-cold lysis buffer was added to ILU-18 cells $\left(1 \times 10^{6}\right)$, incubated on ice for $10 \mathrm{~min}$, and centrifuged at $12,000 \times \mathrm{g}$ for $10 \mathrm{~min}$. To this preparation, $2 \mu \mathrm{L}$ of $25 \mathrm{mM}$ monochlorobimane (MCB) and $50 \mathrm{U} / \mathrm{mL}$ glutathione-S-transferase (GST) were added and incubated at $37^{\circ} \mathrm{C}$ for $30 \mathrm{~min}$. At the end of incubation, fluorescence was measured by employing a fluorescence plate reader (Perkin Elmer Corporation, Norwalk, CT, USA) with an excitation wavelength of $340 \mathrm{~nm}$ and emission wavelength of $465 \mathrm{~nm}$. Values obtained in the absence of GST and MCB served as negative controls.

\subsection{Luciferase Reporter Assay}

ILU-18 cells, with or without pretreatment, were activated with pervanadate $(100 \mu \mathrm{M})$ for $18 \mathrm{~h}$ at $37^{\circ} \mathrm{C}$. Additionally, ILU-18 cells were subjected to treatment with $\mathrm{H}_{2} \mathrm{O}_{2}(100 \mu \mathrm{M})$ for $18 \mathrm{~h}$ or $200 \mu \mathrm{M}$ Buthionine-sulfoximine (BSO) for $24 \mathrm{~h}$ at $37{ }^{\circ} \mathrm{C}$. Utilizing a Luciferase Reporter assay kit (Promega, Madison, WI, USA), lysates were prepared with Reporter lysis buffer by repeated freezing and thawing. Protein content was determined by Bio-Rad assay. Per the supplier's protocol [41], cell extract (50 $\mu$ g protein) was combined with $100 \mu \mathrm{L}$ of the luciferase assay reagent at room temperature and analyzed by luminometer.

\subsection{Statistical Analyses}

Differences between means of the data generated in the study were analyzed using Student's $t$-test. Differences were considered significant, if $p<0.05$.

\section{Conclusions}

The results presented here demonstrate that while proteasome inhibition can potentiate oxidative stress associated with pervanadate stimulation, it fails to influence the induction of NF- $\kappa$ B by the atypical pathway. Thus, the regulation of $\mathrm{I} \kappa \mathrm{B} \alpha$ and upstream signaling pathway intermediates in the atypical

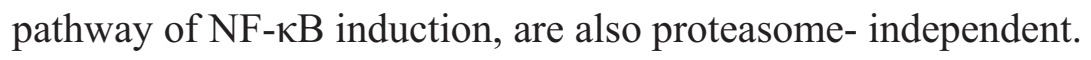




\section{Acknowledgments}

This work was supported by National Institutes of Health Grants, RO1 AG030599 and AG025220 to UP.

\section{Author Contributions}

Sarah Cullen, Usha Ponnappan and Subramaniam Ponnappan designed the study. Sarah Cullen performed and analyzed majority of the experiments outlined in the manuscript. Sarah Cullen and Subramaniam Ponnappan, analyzed and interpreted the data. Subramaniam Ponnappan revised and edited the figures. Usha Ponnappan supervised the study. All authors discussed and commented on the study.

\section{Conflicts of Interest}

The authors declare no conflicts of interest.

\section{References}

1. Pahl, H.L. Activators and Target Genes of Rel/NF-kB Transcription Factors. Oncogene 1999, 18, 6853-6866.

2. Li, N.; Karin, M. Is NF-кB the Sensor of Oxidative Stress? FASEB J. 1999, 13, 1137-1143.

3. Janssens, S.; Tschopp, J. Signals From Within: The DNA-Damage-Induced NF-кB Response. Cell Death Differ. 2006, 13, 773-784.

4. Pahl, H.L.; Baeuerle, P.A. A novel signal transduction pathway from the endoplasmic reticulum to the nucleus is mediated by transcription factor NF-кB. EMBO J. 1995, 14, 2580-2588.

5. Hayden, M.S.; Ghosh, S. Shared Principles in NF-кB Signaling. Cell 2008, 132, 344-362.

6. Canty, T.G., Jr.; Boyle, E.M., Jr.; Farr, A.; Morgan, E.N.; Verrier, E.D.; Pohlman, T.H. Oxidative stress induces NF- $\kappa \mathrm{B}$ nuclear translocation without degradation of $\mathrm{I} \kappa \mathrm{B} \alpha$. Circulation 1999, 100, II361-II364.

7. Imbert, V.; Rupec, R.A.; Livolsi, A.; Pahl, H.L.; Traenckner, E.B.; Mueller-Dieckmann, C.; Farahifar, D.; Rossi, B.; Auberger, P.; Baeuerle, P.A.; et al. Tyrosine phosphorylation of IкB $\alpha$

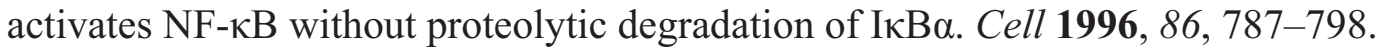

8. Beraud, C.; Henzel, W.J.; Baeuerle, P.A. Involvement of regulatory and catalytic subunits of phosphoinositide 3-kinase in NF-кB activation. Proc. Natl. Acad. Sci. USA 1999, 96, 429-434.

9. Heffetz, D.; Bushkin, I.; Dror, R.; Zick, Y. The insulinomimetic agents $\mathrm{H}_{2} \mathrm{O}_{2}$ and vanadate stimulate protein tyrosine phosphorylation in intact cells. J. Biol. Chem. 1990, 265, 2896-2902.

10. Yaname, H.; Fukunaga, T.; Nigorikawa, K.; Okamura, N.; Ishibashi, S. Pervanadate activates NADPH oxidase via protein kinase C-independent phosphorylation of p47-phox. Arch. Biochem. Biophys. 1999, 361, 1-6.

11. Chiarugi, P.; Buricchi, F. Protein tyrosine phosphorylation and reversible oxidation: Two cross-talking posttranslation modifications. Antioxid. Redox Signal. 2007, 9, 1-24.

12. Fan, C.; Li, Q.; Ross, D.; Engelhardt, J.F. Tyrosine Phosphorylation of $\mathrm{I} \kappa \mathrm{B} \alpha$ Activates NF $\kappa \mathrm{B}$ through a redox-regulated and c-Src-dependent mechanism following hypoxia/reoxygenation. J. Biol. Chem. 2003, 278, 2072-2080. 
13. Bui, N.T.; Livolsi, A.; Peyron, J.F.; Prehn, J.H. Activation of nuclear factor $\kappa B$ and Bcl-x Survival gene expression by nerve growth factor requires tyrosine phosphorylation of $\mathrm{I} \kappa \mathrm{B} \alpha . J$. Cell Biol. 2001, 152, 753-764.

14. Gallagher, D.; Gutierrez, H.; Gavalda, N.; O’Keeffe, G.; Hay, R.; Davies, A.M. Nuclear Factor-кB activation via tyrosine phosphorylation of inhibitor $\kappa \mathrm{B}-\alpha$ is crucial for ciliary neurotrophic factor-promoted neurite growth from developing neurons. J. Neurosci. 2007, 27, 9664-9669.

15. Mahabeleshwar, G.H.; Kundu, G.C. Tyrosine kinase P56lck regulates cell motility and nuclear factor $\kappa \mathrm{B}$-mediated secretion of urokinase type plasminogen activator through tyrosine phosphorylation of IкB $\alpha$ following hypoxia/reoxygenation. J. Biol. Chem. 2003, 278, 52598-52612.

16. Natarajan, R.; Fisher, B.J.; Jones, D.G.; Fowler, A.A., III. Atypical Mechanism of NF-кB activation during reoxygenation stress in microvascular endothelium: A role for tyrosine kinases. Free Radical Biol. Med. 2002, 33, 962-973.

17. Sethi, G.; Ahn, K.S.; Chaturvedi, M.M.; Aggarwal, B.B. Epidermal growth factor (EGF) activates nuclear factor- $\kappa \mathrm{B}$ through $\mathrm{I} \kappa \mathrm{B} \alpha$ kinase-independent but EGF receptor-kinase dependent tyrosine 42 phosphorylation of IкBa. Oncogene 2007, 26, 7324-7332.

18. Markovina, S.; Callander, N.S.; O’Connor, S.L.; Kim, J.; Werndli, J.E.; Raschko, M.; Leith, C.P.; Kahl, B.S.; Kim, K.; Miyamoto, S. Bortezomib-resistant nuclear factor- $\kappa$ B activity in multiple myeloma cells. Mol. Cancer Res. 2008, 6, 1356-1364.

19. Yang, D.T.; Young, K.H.; Kahl, B.S.; Markovina, S.; Miyamoto, S. Prevalence of bortezomib-resistant

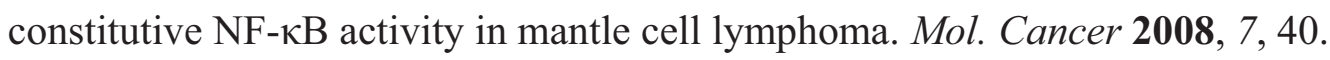

20. Cullen, S.J.; Ponnappan, S.; Ponnappan, U. proteasome inhibition up-regulates inflammatory gene

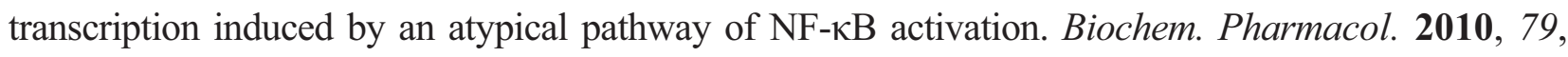
706-714.

21. Livolsi, A.; Busuttil, V.; Imbert, V.; Abraham, R.T.; Peyron, J.F. Tyrosine phosphorylation-dependent activation of NF-kB. Requirement for p56 LCK and ZAP-70 protein tyrosine kinases. Eur. J. Biochem. 2001, 268, 1508-1515.

22. Zhao, Z.; Tan, Z.; Diltz, C.D.; You, M.; Fischer, E.H. Activation of mitogen-activated protein (MAP) kinase pathway by pervanadate, a potent inhibitor of tyrosine phosphatases. J. Biol. Chem. 1996, 271, 22251-22255.

23. Holbrook, N.J.; Ikeyama, S. Age-related decline in cellular response to oxidative stress: Links to growth factor signaling pathways with common defects. Biochem. Pharmacol. 2002, 64, 999-1005.

24. Storz, P.; Toker, A. Protein kinase D mediates a stress-induced NF- $\kappa$ B activation and survival pathway. EMBO J. 2003, 22, 109-120.

25. Cullen, S.; Ponnappan, S.; Ponnappan, U. Department of Microbiology and Immunology, UAMS, Little Rock, AR, USA. Unpublished data, 2009.

26. Krejsa, C.M.; Nadler, S.G.; Esselstyn, J.M.; Kavanagh, T.J.; Ledbetter, J.A.; Schieven, G.L. Role of oxidative stress in the action of vanadium phosphotyrosine phosphatase inhibitors. Redox independent activation of NF-кB. J. Biol. Chem. 1997, 272, 11541-11549.

27. Hakak, Y.; Martin, G.S. Ubiquitin-dependent degradation of active Src. Curr. Biol. 1999, 9, 1039-1042.

28. Harris, K.F.; Shoji, I.; Cooper, E.M.; Kumar, S.; Oda, H.; Howley, P.M. Ubiquitin-mediated degradation of active Src tyrosine kinase. Proc. Natl. Acad. Sci. USA 1999, 96, 13738-13743. 
29. Crevecoeur, J.; Merville, M.P.; Piette, J.; Gloire, G. Geldanamycin inhibits tyrosine phosphorylation-dependent NF-кB activation. Biochem. Pharmacol. 2008, 75, 2183-2191.

30. Kawai, H.; Nie, L.; Yuan, Z.M. Inactivation of NF-кB-dependent cell survival, a novel mechanism for the proapoptotic function of C-Abl. Mol. Cell. Biol. 2002, 22, 6079-6088.

31. Waris, G.; Livolsi, A.; Imbert, V.; Peyron, J.F.; Siddiqui, A. Hepatitis C virus NS5A and subgenomic replicon activate NF- $\mathrm{NB}$ via tyrosine phosphorylation of $\mathrm{I} \kappa \mathrm{B} \alpha$ and its degradation by calpain protease. J. Biol. Chem. 2003, 278, 40778-40787.

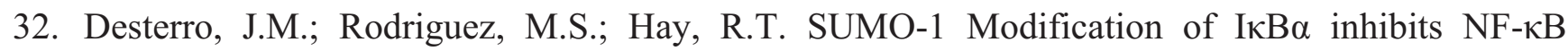
activation. Mol. Cell 1998, 2, 233-239.

33. Singh, S.; Darnay, B.G.; Aggarwal, B.B. Site-specific tyrosine phosphorylation of IкB $\alpha$ negatively regulates its inducible phosphorylation and degradation. J. Biol. Chem. 1996, 271, 31049-31054.

34. Ding, Q.; Reinacker, K.; Dimayuga, E.; Nukala, V.; Drake, J.; Butterfield, D.A.; Dunn, J.C.; Martin, S.; Bruce-Keller, A.J.; Keller, J.N. Role of the proteasome in protein oxidation and neural viability following low-level oxidative stress. FEBS Lett. 2003, 546, 228-232.

35. Du, Z.X.; Zhang, H.Y.; Meng, X.; Guan, Y.; Wang, H.Q. Role of oxidative stress and intracellular glutathione in the sensitivity to apoptosis induced by proteasome inhibitor in thyroid cancer cells. BMC Cancer 2009, 9, 56.

36. Fernandes, A.F.; Zhou, J.; Zhang, X.; Bian, Q.; Sparrow, J.; Taylor, A.; Pereira, P.; Shang, F. Oxidative inactivation of the proteasome in retinal pigment epithelial cells. A potential link between oxidative stress and up-regulation of Interleukin-8. J. Biol. Chem. 2008, 283, 20745-20753.

37. Papa, L.; Rockwell, P. Persistent mitochondrial dysfunction and oxidative stress hinder neuronal cell recovery from reversible proteasome inhibition. Apoptosis 2008, 13, 588-599.

38. Sullivan, P.G.; Dragicevic, N.B.; Deng, J.H.; Bai, Y.; Dimayuga, E.; Ding, Q.; Chen, Q.; Bruce-Keller, A.J.; Keller, J.N. Proteasome inhibition alters neural mitochondrial homeostasis and mitochondria turnover. J. Biol. Chem. 2004, 279, 20699-20707.

39. Alexandrova, A.; Petrov, L.; Georgieva, A.; Kessiova, M.; Tzvetanova, E.; Kirkova, M.; Kukan, M. Effect of MG132 on proteasome activity and prooxidant/antioxidant status of rat liver subjected to ischemia/reperfusion injury. Hepatol. Res. 2008, 38, 393-401.

40. Das, R.; Ponnappan, S.; Ponnappan, U. Redox regulation of the proteasome in T lymphocytes during aging. Free Radical Biol. Med. 2007, 42, 541-551.

41. Wood, K.V. Firefly luciferase: A new tool for molecular biologists. Promega Notes 1990, $28,1-3$.

(C) 2015 by the authors; licensee MDPI, Basel, Switzerland. This article is an open access article distributed under the terms and conditions of the Creative Commons Attribution license (http://creativecommons.org/licenses/by/4.0/). 